Journal of Finance and Banking Review

Journal homepage: www.gatrenterprise.com/GATRJournals/index.html

J. Fin. Bank. Review 2 (1) 9 - 16 (2017)

\title{
Formalizing the investment selection process of the Development Bank of Kazakhstan
}

\author{
Dulat Shukayev $^{1}$, Zhanar Lamasheva ${ }^{2 *}$, Almira Ayapbergenova ${ }^{3}$ and Bimurat Z. ${ }^{4}$ \\ 1,2,3,4 NJSC “Kazakh national research technical university named after K.I. Satpayev”, Satpayev 22, 050013, Almaty, Republic of
} Kazakhstan

\begin{abstract}
Objective - This article presents a functional diagram for implementing the investment program of the Development Bank of Kazakhstan and builds an outline of the pre-investment evaluation process.

Methodology/Technique - A stepwise algorithm is created to conduct a preliminary appraisal of business proposals, and the criteria for assessing the borrower's condition are identified. Key criteria used in the investment performance analysis are discussed. The article develops a computer simulation approach to analysis and decision-making with respect to investment programs, with consideration of analytically non-formalisable stochastic distributions of parameters and processes. The paper also proposes a new method for optimizing the allocation of funds, given various priorities and risks, taking into account the instability and possible ill-conditioning of the optimization problem.

Findings - The article formalizes the main stages of Development Bank's pre-investment activities in support of the government's innovative industrial development policy in the country's economy

Novelty - Presented models and algorithms of the functional tasks for implementation of investment activities are sufficiently general to be relevant, not only for implementing the government's strategy in this direction, but also for the business interests of any bank or investment entity.
\end{abstract}

Type of Paper: Review

Keywords: Investment Selection Process; Development Bank of Kazakhstan; Investment Activities; Business Proposals; Optimizing.

JEL Classification: G11, G21.

\section{Introduction}

One of the key directions of Kazakhstan's economic policy is a program of economic diversification and the development of new internationally competitive industries with high value added component. The primary task of the Development Bank established to implement this program is to finance projects with higher expected payoff in terms of return on investment and social significance. For obvious reasons, all economic projects contain an element of risk. Therefore, the anticipated payoff must be forecasted with consideration of various random events and shocks. The allocation of funds under these conditions requires a systemic approach

\footnotetext{
* Paper Info: Received: January 5, 2017

Accepted: February 27, 2017

* Corresponding author:

E-mail: zhanarlb@mail.ru

Affiliation: NJSC, Kazakhstan
} 
to the project selection process and to the appraisal of their anticipated payoffs and risks. The growth of the investment operations of all Kazakhstan's banks, including that of the Development Bank, is constrained by a number of factors, such as the limited practical experience with investment activities on the part of Kazakhstan's banks, as well as the fact that the development of general banking strategies in Kazakhstan is still in the initial stages of its formation.

As discussed in Mehran and Stultz (2007), the many potential conflicts of interest for investment banks are typically accompanied by a variety of mechanisms that control the impact of conflicts of interest. The literature has ignored the large portfolios of publicly traded assets operated by investment banks with the exception of Massa and Rehman (2008) and Ritter and Zhang (2007), both of whom focus on bank operated mutual funds. This is surprising given that investment banking is highly regulated and, now, publicly supported.

\section{Methodology}

\subsection{Materials}

The theoretical and practical aspects of bank investment strategies were analyzed by multiple researchers. Their studies examine various theoretical aspects of investment project selection with consideration of risks, as well as the tasks of a financial and economic evaluation of investment processes, and the development of an integrated system for information support of banking and investment decisions. An analysis of these studies shows that the emphasis is on general approaches to managing the investment activities of banks, which does not reflect well the problem of formulating and managing a bank's investment policy from the standpoint of government support for the development of new high value-added competitive industries.

In addition, questions about managing a bank's investment activity require further developments that allow one to simulate possible outcomes of decision-making under the unstable economic parameters and processes with high risk levels typical of the modern economic environment. Therefore, this article develops a computer simulation approach to analyzing and decision-making with respect to investment programs, with consideration of analytically non-formalisable stochastic distributions of parameters and processes, and also proposes a new method for optimizing the allocation of funds, given various priorities and risks, admitting the instability and ill-conditioning of the optimization problem.

\subsection{Research objective}

In most countries, national development institutions play a key role in sustaining economic growth, and in providing stabilizing effects during crises. In the Republic of Kazakhstan the Development Bank of Kazakhstan (DBK) carries out this mission. At present, DBK acts as a facilitator and coordinator of large investment projects, and serves as the link between businesses and the government, since business establishments in Kazakhstan are still not capable of independently developing large, complex projects, especially in the non-resource sector. In a broader sense, the mission of DBK consists in facilitating the achievement of sustainable long-term economic development of the Republic of Kazakhstan by committing some amount of investment loans $(S)$ to finance the loan requirements $(C)$ of competitive non-resource sectors of the country's economy, which are not being funded by second-tier banks (Fig. 1). 


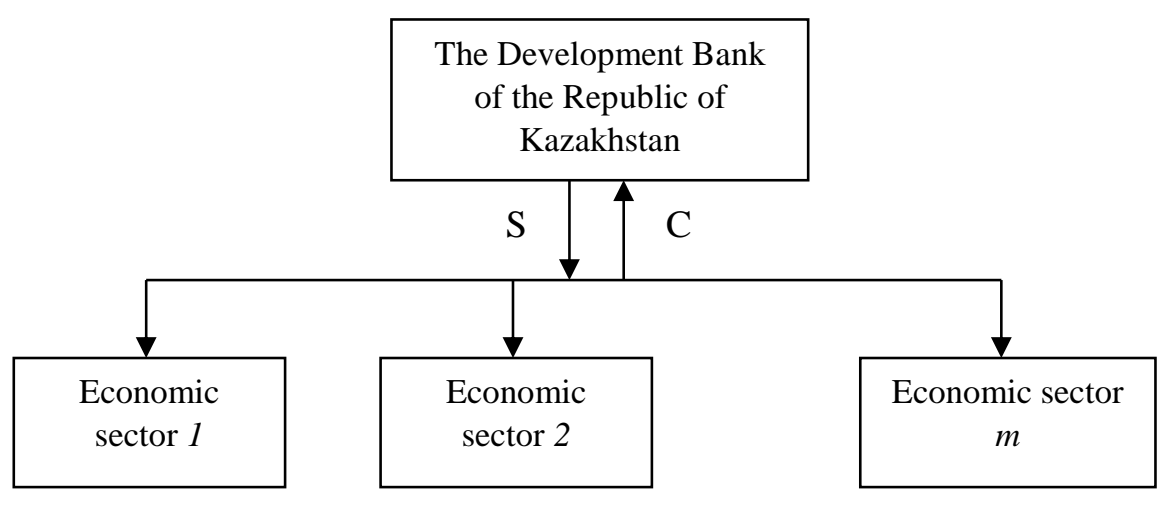

Figure 1. General outline of the research object

According to the Law "On Banks and Banking Activity in the Republic of Kazakhstan", DBK has a special legal status defined by the Law, under which its mission is to improve and increase the effectiveness of government investment activities, to develop production infrastructure of the manufacturing industry, and to provide assistance in attracting foreign and domestic investments into the country's economy (Development Bank of Kazakhstan, 2014).

\subsection{The functional diagram for implementing the investment program of the Development Bank of Kazakhstan}

The Bank's business units perform the following main procedures associated with preparation of an investment program (Fig. 2):

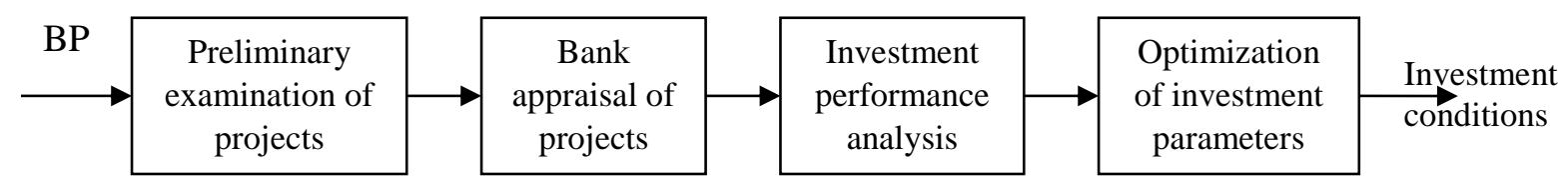

Figure 2. The pre-investment process

The first procedure involves a preliminary appraisal of borrowers' business proposals. The second stage typically includes an appraisal of the company's current and future expected condition, its probable growth rate, its ability to mobilize available sources of funds and the company's standing on the capital markets. The next procedure uses forecasts and calculations of key financial ratios of the projects (net present value, cash flows, discount factors, etc.) to form a preliminary assessment of an expected investment performance. The fourth procedure is devoted to finding optimal investment parameters.

\subsection{Preliminary Appraisal of Business Proposals (BP)}

The following algorithm for a preliminary appraisal of business proposals well represents the actual guidelines used at DBK for examining, financing, monitoring and implementing investment projects (The guidelines, 2004):

Step 1. Checking the applicant's document package for completeness and consistency. If additional information must be provided and/or there are deficiencies in the submitted documents, the bank requests additional documents from the applicant.

Step 2. A background check of the applicant based on a questionnaire. If the information in the applicant's questionnaire is incorrect, the bank rejects the business proposal (BP) and goes to step 9 . 
Step 3. Checking the applicant's involvement in cases of money laundering and crime financing. If any such involvement is discovered, the bank rejects the BP and goes to step 9.

Step 4. Investigation of the contracting parties and a preliminary examination of the content of the project and of its consistency with the Bank's current priorities specified in the Memorandum on Lending Policy. If the BP is inconsistent with the Bank's current priorities, the Bank withdraws the project from examination and goes to step 9 .

Step 5. Checking the credit history of the contracting parties. If there is an unfavorable credit history, the Bank withdraws the BP from examination and moves to step 9.

Step 6. Inspecting the business location and the offered collateral.

Step 7. Preparing the Terms and Conditions for financing.

Step 8 . The conclusion of a confidential agreement about financing, reporting and about the bank's appraisal of the project.

Step 9. The end

\subsection{The assessment of the borrower's current conditions and future prospects}

An assessment of the company's financial position is based on the data from its financial reports for the previous periods and on other available technical and economic reports. The items below provide a brief list of general financial indicators that are typically used for this assessment and which are broken into four broad categories (Smolyak, 2002; Haixiang, Zeng, \& Chen, 2013).

I. Liquidity ratios (used for assessing a company's ability to meet its short-term obligations):

- current ratio - the ratio of current assets to current liabilities. The values of this ratio greater than 1.6 - 2.0 usually mean that the company has a satisfactory liquidity position.

- intermediate liquidity ratio - the ratio of current assets less inventory value to current liabilities. The values of this ratio greater than 1.0 - 1.2 typically signify that the company has a satisfactory liquidity position.

- quick ratio, acid test ratio - the ratio of highly liquid assets to current liabilities. The values of this ratio in excess of $0.8-1.0$ usually mean that the company has a satisfactory liquidity position.

- II. Solvency ratios:

- financial stability ratio - the ratio of the company's equity and subsidies to borrowed funds. Banks generally analyze this ratio when deciding whether to provide long-term loans.

- debt ratio - the ratio of borrowed funds (total long-term and short-term debt) to equity.

- long-term debt ratio - the ratio of long-term debt to total assets.

- long-term debt coverage ratio - the ratio of the net income to the amount of long-term debt payments (repayment of loans + interest).

- III. Turnover ratios (used for assessing the effectiveness of pricing, marketing and procurement operations and policy):

- asset turnover ratio - the ratio of sales revenue to average asset value in the period.

- equity turnover ratio - the ratio of sales revenue to average equity value for the period.

- inventory turnover ratio - the ratio of sales revenue to average inventory value for the period.

- receivables turnover ratio - the ratio of revenue from sales made on credit to average receivables for the period.

- average payable period - the ratio of short-term payables (bills payable) to the costs of purchasing goods and services multiplied by the number of days in the accounting period.

- IV. Profitability ratios (used to assess the current profitability of a company participating in a project):

- return on sales - the ratio of profits before taxes to the amount of revenue from the sale of products and non-sale operations. 
- return on assets - the ratio of profit before tax to asset value.

- return on equity - the ratio of net profit to the average equity value for the period.

This list may be supplemented at the request of individual project participants or financial institutions, or due to the introduction by government agencies of new or modified criteria for initiating bankruptcy proceedings against a company.

It is advisable to analyze the values of the respective ratios over time and compare them to the ratios of similar companies. Each project participant, the lending banks and leasing companies may have their own standards of the limiting values of these ratios indicating a company's unsound financial condition. However, in general, these indicators depend on the industrial structure and on the valuation practices for the inputs and outputs. Therefore, it is not always reasonable to use the current values of the financial indicators existing as of the calculation time to appraise a company's financial position over a prolonged implementation period of an investment project.

\section{Investment Performance Analysis}

There are several methods for evaluating the attractiveness of an investment project and several key criteria for choosing a particular project. Each method is based on an important principle, according to which the investor should make a profit from implementing the project. Furthermore, the various financial ratios describe the project from different perspectives according to the interests of various related parties associated with the investor.

The key criteria used in investment analysis (overall performance) include (Gracheva, 2007):

- Net Present Value, NPV

$$
N P V=-K+\sum_{t=1}^{t=T} \frac{R(t)-C(t)}{\prod_{S=1}^{S=t}\left(1+E_{S}\right)}
$$

where $K$ represents the initial investments; $R(t)$ is the cash inflow in year $t ; C(t)$ is the cash outflow in year $t ; T$ is the life time of the project; $E_{s}$ is the discount rate.

- Internal Rate of Return, IRR, is found as the root of the equation

$$
-K+\sum_{t=1}^{t=T} \frac{R(t)-C(t)}{(1+I R R)^{t}}=0
$$

$$
P I=\frac{\sum_{t=1}^{t=T} \frac{R(t)-C(t)}{\prod_{S=1}^{S=t}\left(1+E_{S}\right)}}{K} ;
$$


- Payback Period, $P P$, is the minimum length of time after which $N P V$ becomes and remains nonnegative.

All performance indicators (overall performance) are calculated with discounted cash flows representing cash inflows or cash receipts, and cash outflows or cash payments during project implementation.

$N P V$ indicates a direct increase in the company's capital; therefore, it is the most important indicator for the company's shareholders.

A positive value of $N P V$ at a previously set discount rate is the main criterion for accepting a project.

Payback period acts as a limiting condition during an investment project performance evaluation. Some companies use a project classification system in which the payback period indicates how quickly each of them must be implemented.

The IRR indicator is independent of the discount rate. It may be calculated either by computer or manually by trial and error. According to the internal rate of return rule, an investment project should be accepted if the opportunity costs of raising capital are less than the internal rate of return, i.e., $I R R>r$. If the opportunity costs are equal to the internal rate of return, the project has zero $N P V$. When several projects are being compared, projects with higher IRR values are preferable.

In order to avoid the problem of multiple rates of return, an analog to $I R R$ - modified internal rate of return $(M I R R)$ - is often calculated. To do this, the positive cash inflows are assumed to be reinvested at the firm's cost of capital.

The following condition is a criterion for deciding to implement an investment project: $M I R R>\mathrm{r}$. The result must always be complemented with the $N P V$ criterion.

It must be emphasized that $M I R R$ should be calculated for any project and regarded as an additional information indicator.

$M I R R$ has one important advantage over IRR: its calculation assumes that earned income is not reinvested at the $I R R$ rate, but rather at a rate equal to a discount rate which in its turn is close or equal to the average market rate of return. The market rate of return is closer to the actual cost of funds and therefore is a more precise measure of the return on the project being appraised.

\section{Results}

Given DBK's stated lending objective of accelerated development of competitive non-resource sectors of the economy we may formulate its loan allocation optimization problem in various ways. First, we will consider the problem of allocating the financial assets in the amount $S$, approved by the government, for innovative development of $K$ specific economic sectors.

Formally, the bank's task may look like this:

$$
\max _{X_{i}^{k} \geq 0} E_{0}\left[\sum_{k=1}^{K} \sum_{i=1}^{n^{k}}\left(X_{i}^{k} \sum_{t=0}^{T} \beta^{t} \gamma_{i, t}^{k}\right)\right]-\delta \times \operatorname{var}\left[\sum_{n=1}^{K} \sum_{i=1}^{n^{k}}\left(X_{i}^{k} \sum_{t=0}^{T} \beta^{t} \gamma_{i, t}^{k}\right)\right]
$$

subject to satisfying the following constraints

$$
\sum_{i=1}^{n^{k}} X_{i}^{k} \leq w \times S \text { for all sectors } k=1,2, \ldots, K
$$


We use the following symbols in the problem posed above:

1) $X_{i}^{k} \geq 0$ - cash investments in company $i$ from sector $k$, where $i=1,2, \ldots, n^{k}$;

2) $E_{0}\left[\sum_{k=1}^{K} \sum_{i=1}^{n^{k}}\left(X_{i}^{k} \sum_{t=0}^{T} \beta^{t} \gamma_{i, t}^{k}\right)\right]$ is the expected value of all future payments received from borrowing companies, from the standpoint of the initial period 0 ;

3) $\beta \in(0,1)$ is the discount factor used by the bank in order to evaluate payments from future quarters (usually $\beta=\frac{1}{1+R}$, where $R$ is the (quarterly) interest rate the bank must pay on its debts);

4) Index $T$ is the maximum number of quarters in which at least some companies must repay their loans (maximum loan term);

5) $K$ is the number of different sectors. The number $n^{k}$ is the number of companies from sector $k$ that the bank is considering for inclusion in its portfolio;

6) $w$ is the limiting value of the share of funds allocated to each sector;

7) $\gamma_{i, t}^{k}$ is the payment of company $i$ from sector $k$ in quarter $t$.

This problem belongs to the class of nonlinear mathematical programming problems with a quadratic objective function, and its solution does not present any fundamental difficulties provided it is well conditioned. If the parameters of the problem are ill-conditioned or disturbed by small parameters, one can use the "extension method" which starts with an extended set of feasible solutions, and then converges to the optimal solution of an ill-conditioned problem (Shukayev, D., Kim, Shukayev, M., Ergalieva, \& Mereke, 2012; Shukayev, Abdullina, Yergaliyeva, \& Lamasheva, 2014).

\section{Discussion}

The article formalizes the main stages of Development Bank's pre-investment activities in support of the government's innovative industrial development policy for the country's economy. We believe that the presented models and algorithms of the functional tasks for implementation of investment activities are sufficiently general to be relevant, not only for implementing the government's strategy in this direction, but also for the business interests of any bank or investment entity.

In future studies, we expect to construct models and algorithms for each of the given stages in order to analyze, plan, forecast and prepare recommendations for decision-making, not only at each of these stages, but also for implementing an investment project as a whole. The analysis of a number of contemporary works in this area (Lukasevich, 1998) shows that this will require the development of simulation methods for analyzing and optimizing all stages of investment management.

\section{References}

Development Bank of Kazakhstan (2014). Industrial Development with Development Bank of Kazakhstan (DBK). Retrieved from: http://www.dbk.kz/en/about/reports/

Gracheva, M.V. (2007). Investment Project Risk Analysis. Moscow: UNITY.

Haixiang, Y., Zeng, Y. \& Chen Sh. (2013). Multi-period mean-variance asset-liability management with uncontrolled cash flow and uncertain time-horizon. Economic Modelling. 30(C), 492-500. 
Lukasevich, I.Ya. (1998). Financial Transaction Analysis. Moscow: Finance.UNITY.

Massa, M., \& Rehman, Z. (2008). Information flows with financial conglomerates: evidence from the banks-mutual funds relation. Journal of Financial Economics. 89, 288-306.

Mehran, H. \& Stulz, R. (2007). The economics of conflicts of interest in financial institutions. Journal of Financial Economics. 85, 267-296.

Ritter, J. \& Zhang, D. (2007). Affiliated mutual funds and the allocation of initial public offerings. Journal of Financial Economics. 86, 337-368.

Shukayev, D.N., Kim, E.R., Shukayev, M.D., Ergalieva, N.O. \& Mereke, A.A. (2012). Modeling resource flows and allocations in systems with parallel structure. Proceedings of the IASTED International Conference Applied Simulation and modelling (p. 57-63). Napoli, Italy.

Shukayev, D.N., Abdullina, V.Z., Yergaliyeva, N.O. \& Lamasheva, Zh.B. (2014). Modeling the processes of distribution of resource flows. Proceedings of the Romanian academy, Series A, 15(1), 85-94.

Smolyak, S.A. (2002). Investment Project Performance Evaluation under Risk and Uncertainty. Moscow: Nauka.

The guidelines for evaluation of an investment project effectiveness [an electronic resource]. (2004). The institute of Systems Analysis of the RAS, Central Economics and Mathematics Institute of the RAS, et al., Moscow. Retrieved from: tpp74.ru/storage/invest_metodikam.doc 